\title{
Formulation development of directly compressed Naproxen SR tablet using Kollidon SR and Avicel PH 102 polymer
}

\author{
Dilshad Yasmin, *Md. Rashidur Rahman, Morshada Akter \\ Department of Pharmacy, Stamford University Bangladesh, 51, Siddeswari Road, Dhaka-1217, Bangladesh
}

\begin{abstract}
Naproxen is a well-known non-steroidal anti-inflammatory drug (NSAID). This work has been done for developing a formulation of $280 \mathrm{mg}$ sustained release (SR) tablet where $150 \mathrm{mg}$ active pharmaceutical ingredient (Naproxen) were used along with other excipients like Kollidon SR, Avicel PH 102, Lactose MH, Povidone K 30 and Mg-Stearate. Naproxen SR tablet was prepared by direct compression method aiming to enhance its dissolution properties. The physical parameters (hardness, thickness, diameter, average weight and friability) and drug release profile of this tablet were evaluated. The hardness of tablets from F1 and F2 formulation were highest and rest of them was also satisfactory. F2 formulation did not meet the friability test. But rests of the formulations were acceptable which indicate that others formulations can handle pressure during storage, transportation and packaging. All the formulations released $90 \%$ of drug within 120 minutes except F4 formulation. Among the six formulations, release was prompt in F1 formulation because of usage of higher concentration of polymer Kollidon SR. The outcome of this study indicates that the rate of dissolution of Naproxen SR tablet can be considerably improved with Kollidon SR.
\end{abstract}

Key Words: Non-steroidal anti-inflammatory drug, Naproxen, sustained release, direct compression, formulation, Kollidon SR.

\section{INTRODUCTION}

Naproxen (S)-6-methoxy- $\alpha$-methyl-2-naphthalene acetic acid, is a widely used non-steroidal anti-inflammatory drug in the treatment of rheumatoid arthritis. It has been used for a long time because of its efficacy and safety profile (Ahmed et al., 2010). This drug is recognized to be highly effective and clinically safe, but some side-effects such as gastrointestinal toxicity, nephrotoxicity, jaundice and hepatotoxicity have been reported (Hiroyuki et al., 2006). This drug may rarely cause severe (rarely incurable) bleeding from the stomach or intestines. Older adults may be at higher risk for this effect (Aronson et al., 2010). Naproxen is used to relieve pain from various conditions such as headaches, muscle aches, tendonitis, dental pain and menstrual cramps. It also reduces pain; swelling and joint stiffness caused by arthritis, bursitis and gout attacks. It works by blocking body's production of certain natural substances that cause inflammation (Manrique-Moreno et al., 2010). Development of sustained release oral dosage forms is beneficial for optimal therapy in terms of efficacy, safety and patient compliance. Ideally, a controlled release dosage form will provide therapeutic concentration of the drug in the blood that is maintained throughout the dosing interval (Javadzadeh et al., 2008). The present study investigates the formulation of directly compressed SR tablets of Naproxen, by using a combination of polymers (Kollidon SR and Avicel PH 102). Kollidon SR is a free-flowing non hygroscopic powder consisting of polyvinyl acetate $(80 \%, \mathrm{w} / \mathrm{w})$ and polyvinylpyrrolidone $(20 \%, \mathrm{w} / \mathrm{w})$ combined as a physical mixture. It has a unique character of maintaining tablets geometric shape until the end of dissolution test, this is mainly due to its major component; the water insoluble polyvinyl acetate, while the minor water soluble part;

\begin{tabular}{l}
\hline \hline *Corresponding Author: \\
Md. Rashidur Rahman, Lecturer \\
Department of Pharmacy \\
Stamford University Bangladesh \\
51 Siddeswari Road, Dhaka-1217, Bangladesh \\
E-mail: sumon_pharmacy@yahoo.co.uk \\
Contact No.:+8801727510 926
\end{tabular}

polyvinylpyrrolidone, is responsible for pore formation causing diffusion controlled release mechanism (Sark et al., 2010). Avicel PH-102 is reported to exhibit better flow. The denser version of PH 101, PH 102, PH 301 and PH 302 , respectively has improved flow property but reduce compressibility. Avicel PH 102 exhibited lower crushing strength and shorter disintegration time than Avicel $\mathrm{PH}$ 101 (Gad, 2008). In this study, an attempt was made to formulate directly compressed Naproxen sustained release tablet by using Kollidon SR and Avicel PH 102. The physical parameters (hardness, thickness, diameter, average weight and friability) and drug release profile of this tablet were evaluated.

\section{MATERIALS AND METHODS}

\section{Formulation}

The formulation of directly compressed Naproxen SR tablet was developed in this study. The ingredients used in the formulation are listed in table 1 along with justification of uses of each ingredient.

\section{Direct compression method}

It is known as direct compression because direct compression consists of compressing tablet directly from powder material without modifying the physical nature of the material itself (Beringer et al., 2005). This method does not require any type of granulation either dry or wet granulation. Here drug, binder, diluents, lubricant are directly compressed by compression machine. Tablet production by direct compression involves only two operations in sequence, powder mixing and tableting. The advantage with direct compression is primarily a reduced production cost (Aulton, 2007).

\section{Evaluation of formulated tablets \\ Average weight}

Randomly, 20 tablets were selected after compression from each formulation and the mean weight was determined. None of the tablets deviated from the average weight by more than $\pm 7.5 \%$ (USPXX). The USP has provided 
Table 1: Formulations of Naproxen SR tablets.

\begin{tabular}{|c|c|c|c|c|c|c|c|}
\hline \multirow{2}{*}{ Ingredients } & \multirow{2}{*}{ Justification of use } & \multicolumn{6}{|c|}{ Amount of ingredients (in $\mathrm{mg} /$ tablet) } \\
\hline & & F1 & F2 & F3 & F4 & F5 & F6 \\
\hline Naproxen & API & 150 & 150 & 150 & 150 & 150 & 150 \\
\hline HPMC 15cps & Binder & 28 & 33.6 & 39.2 & 44.8 & 50.4 & 56 \\
\hline Kollidon SR & Polymer & 28 & 22.4 & 16.8 & 11.2 & 5.6 & 0 \\
\hline Povidone K30 & Polymer & 11.2 & 11.2 & 11.2 & 11.2 & 11.2 & 11.2 \\
\hline Avicel PH 102 & Polymer & 36 & 36 & 36 & 36 & 36 & 36 \\
\hline Lactose MH & Diluent & 24 & 24 & 24 & 24 & 24 & 24 \\
\hline Mg-stearate & Lubricant & 2.8 & 2.8 & 2.8 & 2.8 & 2.8 & 2.8 \\
\hline & Total $=$ & 280 & 280 & 280 & 280 & 280 & 280 \\
\hline
\end{tabular}

Table 2: Physical properties of Naproxen SR tablets.

\begin{tabular}{lllllll}
\hline Properties & F1 & F2 & F3 & F4 & F5 & F6 \\
\hline Thickness (mm) & 3.3 & 3.4 & 3.4 & 3.5 & 3.4 & 3.4 \\
Diameter (mm) & 10.5 & 10.5 & 10.4 & 10.4 & 10.4 & 10.4 \\
Hardness (kg/cm $\left.{ }^{2}\right)$ & 6.8 & 6.8 & 5.9 & 4.4 & 5.3 & 4.9 \\
Average Weight $(\mathrm{mg})$ & 279.1 & 278.6 & 275.2 & 277.2 & 277.1 & 275.2 \\
Friability (\%) & 0.8 & 1.1 & 0.8 & 0.2 & 0.8 & 0.4 \\
\%Drug release & 93.9 & 90.0 & 84.4 & 83.4 & 82.4 & 81.4 \\
\hline
\end{tabular}

All readings are average of 3 samples

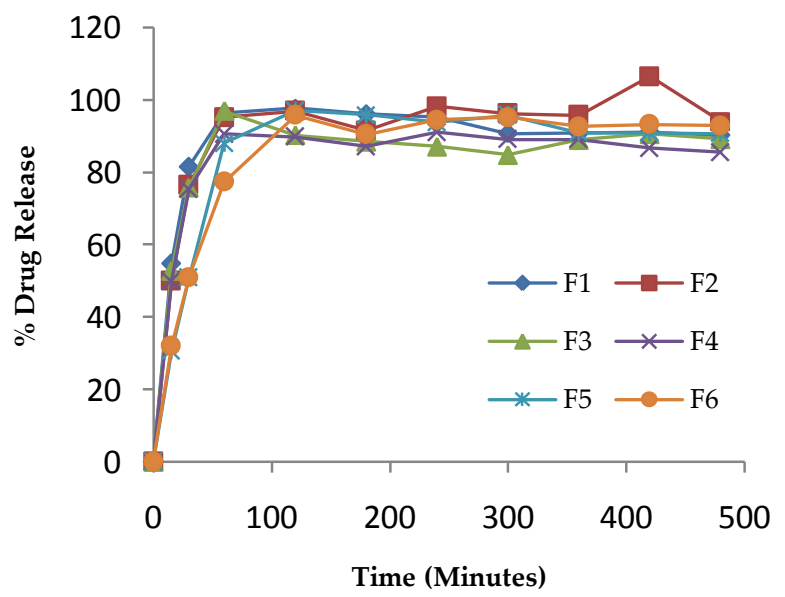

Figure 1: Drug release profile of all formulations (F1-F6) of Naproxen SR tablet.

tolerances for the average weight of uncoated compressed tablets. These are applicable when the tablet contains 50mg or more of the drug substance or when the latter comprises $50 \%$ or more, by weight, of the dosage form.

Hardness test

Ten tablets of each of the formulations were taken and hardness was measured using a Monsanto hardness tester. The average value was calculated (Marshall et al., 1987).

Thickness test

Ten tablets of each of the formulations were taken and thickness was measured by thickness tester and average was calculated.

\section{Friability test}

Ten tablets of each of the formulations were weighed out and taken into the rotating disk of a friability tester. It was allowed to rotate at $25 \mathrm{rpm}$ for 4 minutes (100 revolutions). At the end of the rotation, tablets were collected, dedusted and reweighed. The friability was calculated as the percent of weight loss (Lachman et al., 1990):

Friability $=\frac{\text { Weight Loss }}{\text { Initial Weight }} \times 100$

\section{Dissolution test}

The dissolution test of the formulated tablets was done by paddle method. Agitation is provided by a rotating paddle and the dosage form is allowed to sink to the bottom of the dissolution vessel before agitation is commenced. The dissolution medium should be $0.1 \mathrm{M}$ HCL and pH 7.4 buffer to stimulate the biological extremes according to USP, 2004 (Asian edition).

\section{RESULTS AND DISCUSSION}

The tablets from different formulations (F1-F6) were evaluated for hardness, thickness, diameter, average weight and friability and drug release profile. The results of these physical parameters summarized in the table 2 . All the results calculated from average tablet samples. Thickness, hardness and average weight of all tablet formulations were found to be satisfactory. All formulation passed friability test except formulation F2. More than $90 \%$ of drug released within 120 minutes for all tablet formulation except F4 formulation. Drug release profile of Naproxen SR tablet presented in the Figure 1. Percent dug release against time was depicted in the figure. It was observed that drug release was prompt in case of F1 formulation because of higher concentration of polymer Kollidon SR was used in this formulation. This indicates that release of drug from Naproxen SR tablet is polymer dependant.

\section{CONCLUSION}

In this study direct compression method was used to prepare Naproxen SR tablet to increase their dissolution rate. For this purpose polymer Kollidon SR were used in different proportion in the formulation to see how it affects drug release profile. Physical parameters hardness, thickness and average weight of tablets of different formulations were evaluated and showed satisfactory results. F2 formulation does not meet the friability test but rests of the formulations were good enough which indicate that others formulations can handle pressure during storage, transportation and packaging. Among six formulations, release of F1 formulation was prompt because polymer Kollidon SR was used in higher concentration in this formulation.

\section{REFERENCES}

Ahmed I., Islam M.R., Chowdhury J.A., Islam M.K. and Rahman M.H.

(2010) In vitro release kinetics study of Naproxen from swellable

hydrophilic matrix tablets. Bangladesh Pharmaceutical Journal,

Volume 13, Issue 1, Pages 18-22.

Aronson J.K. and Dukes M.N.G. (2010) Meyler's Side Effects of Drugs (14 $4^{\text {th }}$ ed., p. 264), Elsevier.

Aulton M.E. (2007) The Design and Manufacture of Medicines ( $3^{\text {rd }}$ ed., pp. 296-404), Harcourt Publishers Limited.

Beringer P., Marderosian A.D., Felton L., Gelone S., Gennaro A.R., Gupta P.K., Hoover J.E., Popovick N.G., Reilly W.J. and Hendrickson R. (2005) 
Remington The Science and Practice of Pharmacy (21 ${ }^{\text {st }}$ ed., pp. $889-901$ 906-912; 929-940). B.I Publication Pvt.Ltd.

Gad S.C. (2008) Pharmaceutical manufacturing handbook: production and processes, (Vol.5, .pp. 351-367).Illustrated Publisher, John Wiley \& Sons.

Hiroyuki Y., Toshiharu H. and Shoji A. (2006) Naproxen-induced oxidative stress in the isolated perfused rat liver. Chemico-Biological Interactions, Volume 160, Issue 2, Pages 150-158. [DOI]

Javadzadeh Y., Musaalrezaei L. andNokhodchi A. (2008) Liquisolid technique as a new approach to sustain propranolol hydrochloridereleasefrom tablet matrices. International Journal of Pharmaceutics, Volume 362, Issue (1-2), Pages 102-108. [DOI]
Lachman L., Lieberman H.A. and Kanig J.L. (1990) The Theory and Practice of Industrial Pharmacy (3 ${ }^{\text {rd }}$ ed., pp. 293-335). Mubai: Varghese Publishing House.

Manrique-Moreno M., Suwalsky M., Villena F. and Garidel P. (2010) Effects of the nonsteroidal anti-inflammatory drug naproxen on human erythrocytes and on cell membrane molecular models. Biophysical Chemistry, Volume 147, Issue (1-2), Pages 53-58. [DOI]

Marshall K., Lachman N. and Liberman H. A. (1987) The theory and practice of industrial pharmacy ( $3^{\text {rd }}$ ed., p. 66-69). Mumbai: Varghese Publishing House.

Sakr W., Alanazi F. and Sakr A. (2011) Effect of Kollidon ${ }^{\circledR}$ SR on the release of Albuterol Sulphate from matrix tablets. Saudi Pharmaceutical Journal, Volume 19, Pages 19-27. [DOI] 